\title{
Development of a through-process simulation workflow for spiral pipe forming including evolution of texture and dislocation substructure
}

\author{
Matthias Bönisch $^{\S}$, Hadi Ghiabakloo ${ }^{\S}$, Marc Seefeldt ${ }^{\S}$, Albert Van Bael${ }^{\S}$, Nuria Sanchez ${ }^{\dagger}$ and \\ Steven Cooreman ${ }^{\dagger}$ \\ $\S$ Department for Materials Engineering (MTM), KU Leuven \\ Kasteelpark Arenberg 44, bus 2450, 3001 Leuven, Belgium \\ Web page: www.mtm.kuleuven.be \\ ${ }^{\dagger}$ ArcelorMittal Global R\&D Gent, OCAS NV \\ Pres. J. F. Kennedylaan 3, 9060 Zelzate, Belgium \\ Web page: www.ocas.be
}

\begin{abstract}
Spiral forming is a widely used industrial method for the manufacture of large-diameter welded pipes from levelled steel strip. However, the multi-step helical forming process and post-treatment of the pipe influence the material behavior and alter the final mechanical anisotropy of the product. In addition, the complex microstructures of modern pipeline steels contain various sources of anisotropy including residual stresses, crystallographic and morphologic textures, and directional dislocation substructures [1]. They not only affect the local and global pipe strength, ductility and toughness during monotonic loading but also cause strong strain path effects, e.g. a pronounced Bauschinger effect. Anisotropy thus poses a true challenge to pipeline designers making it difficult to accurately predict the final pipe behavior from the known properties of the hot-rolled high-strength coil, the starting point of the forming process [2]. Still, such predictive power is vital to guarantee the structural integrity of pipelines without failure in case of in-service loads beyond the elastic range.

The manufacturing process can be simplified into two steps: levelling and spiral forming. For subsequent quality control, samples are extracted from the pipe, per standard flattened and tensile tested in hoop direction. With regard to developing a computational twin of the complete manufacturing and testing process, we represent each step by a separate finite element (FE) model. The full through-process simulation workflow thus necessitates tools to transfer the material state between individual FE models. Here, we present such a workflow for the dislocation substructural hardening model by Peeters et al. [3]. For each material point the final macroscopic and microscopic state variables, including residual stress, crystallographic texture and dislocation densities, are first interpolated and then transferred to the next model. In this way, the evolution of different anisotropy sources can be studied starting from coil via pipe and ending with tensile testing.
\end{abstract}

\section{REFERENCES}

[1] M. Bönisch, A. Van Bael, M. Seefeldt, P. Barriobero-Vila, G. Requena, N. Sanchez, S. Cooreman, "Unravelling Anisotropy Evolution during Spiral Pipe Forming: a Multiscale Approach", 23th Int. Conference on Material Forming (ESAFORM 2020), Proc. Manuf., 47, 1434-1441 (2020).

[2] S. Cooreman, D. Van Hoecke, M. Liebeherr, P. Thibaux, M. Yamaguti Enderlin, "Experimental and Numerical Study on the Evolution of Mechanical Properties During Spiral Pipe Forming", 11th Int. Pipeline Conf. (IPC2016), IPC2016-64183 (2016).

[3] B. Peeters, M. Seefeldt, C. Teodosiu, S.R. Kalidindi, P. Van Houtte, E. Aernoudt, "Workhardening/softening behaviour of b.c.c. polycrystals during changing strain paths: Part I. An integrated model based on substructure and texture evolution, and its prediction of the stressstrain behaviour of an IF steel during two-stage strain paths.", Acta Mater., 49, 1607-1619 (2001) 